\title{
Climate change adaptation in disaster-prone communities in Cambodia and Fiji
}

\author{
Andreas Neef a*, Bryan Boruff b, Eleanor Bruce c, Chanrith Ngin a, Natasha Pauli b, Kevin Davies c, \\ Floris van Ogtrop ${ }^{\mathrm{d}}$, Renata Varea ${ }^{\mathrm{e}}$, and Eberhard Weber ${ }^{\mathrm{e}}$ \\ a School of Social Sciences, Faculty of Arts, University of Auckland, Auckland, New Zealand \\ $b$ School of Agriculture and Environment, University of Western Australia, Crawley, Australia \\ c School of Geosciences, Faculty of Science, University of Sydney, Sydney, Australia \\ d School of Life and Environmental Sciences, Faculty of Science, University of Sydney, Sydney, Australia \\ e School of Geography, Earth Sciences \& Environment, The University of the South Pacific, Suva, Fiji \\ * Corresponding author. Email: a.neef@auckland.ac.nz
}

\section{ABSTRACT}

This article examines how rural communities living in flood-prone river basins of Cambodia and Fiji have responded to increasing variability of floods and other natural hazards under the influence of climate change and other risk factors. Particular emphasis is placed on risk perceptions and adaptive strategies of households and communities with regard to regular and catastrophic floods and how the livelihoods of vulnerable groups are affected by floods and other climate-induced disasters. Our research approach integrates the food, water and energy security nexus with the rural livelihood framework. The study aims at identifying the spatial extent and dynamics of flood events and determining the factors that enhance adaptive capacities of flood-affected communities and households. Our study finds that access to resources as well as local socio-cultural contexts are important determinants of coping and adaptation practices at the community and household level in the two countries. Findings also suggest that research participants had a profound understanding of flood flows, extent and impacts that complements knowledge gained from hydrological and remote sensing methods. We conclude that blending local and scientific knowledge is a promising approach to enhancing adaptive capacity and resilience.

\section{INTRODUCTION}

Adaptation to climate change tends to refer to long-term, permanent or ongoing changes made by communities, households or individuals in an attempt to mitigate the impact of future climate-related hazards. Adaptive capacity has been described as the "ability to experiment, innovate and learn, to act on new information in response to change and disturbance", while coping strategies refer more to the "short term responses that allow for survival" (Fernández-Giménez, Batkhishig, Batbuyan, \& Ulambayar, 2015). This study questions this distinction, looking instead at how coping strategies often transition into long-term adaptive change. Challenging the distinction between "adaptation" and "coping" is possible through recognition of how the post-disaster moment blends into a new pre-disaster phase, as well as how disaster response and relief efforts merge into more long-term attempts at risk

\section{KEYWORDS}

Asia-Pacific, Climate change adaptation, Disaster risk management, Local knowledge, Participatory research, Rural livelihoods

\section{DOI}

https://doi.org/10.30852/sb.2020.1142

\section{DATES}

Received: 29 November 2019

Published (online): 25 September 2020

Published (PDF): 20 October 2020

\section{(\$)}

This work is licensed under a Creative Commons Attribution-NonCommercial 4.0 International License.

\section{HIGHLIGHTS}

» Research participants had a good understanding of hazards and appropriate actions.

» Local and scientific knowledge can be combined to alleviate climate-associated risks.

» Socio-cultural factors play a crucial role in disaster risk reduction capabilities. 
reduction. By recognizing post-flood action as both reactive and preventative, this study attempts to be inclusive of the diverse ways in which people make decisions about which changes are acceptable, necessary and desired - cognizant of the fact that in many cases short-term coping strategies may be more appropriate than more permanent attempts at adaptation. Our study also challenges the idea that relocation can be imposed on "at-risk" communities without proper consultation and acknowledgement of new risk factors at the planned relocation site.

Cambodia and Fiji are among the 20 most-at-risk countries according to the WorldRiskReport 2019 (Day et al., 2019), primarily due to their high exposure to climate-related hazards. Cambodia constitutes part of the lower Mekong River Basin which is particularly prone to climatic changes. In analyzing future climate and hydrological scenarios for the Mekong River Basin, Hoang et al. (2016) predict significant temperature increases across the lower Mekong River Basin and increased precipitation in the upper catchment, with a high degree of uncertainty as regards the spatial distribution and direction of rainfall projections for the lower basin. As a small island nation, Fiji is particularly vulnerable to the effects of climate change (Lough, Gupta, Power, Grose, \& McGree, 2015; Chand, Tory, Ye, \& Walsh, 2017). Major consequences include sea-level rise and large-scale climatic events, such as tropical depressions and cyclones that can trigger flash floods, coastal and riverbank erosion, and landslides.

In both countries, strengthening community and household resilience and adaptability is of high priority. For the purpose of this study, we define resilience as the ability of households and communities to remain cohesive and functioning in the face of pressure and extreme perturbations. The objectives of the project are to: (1) identify the spatial extent and dynamics of flood

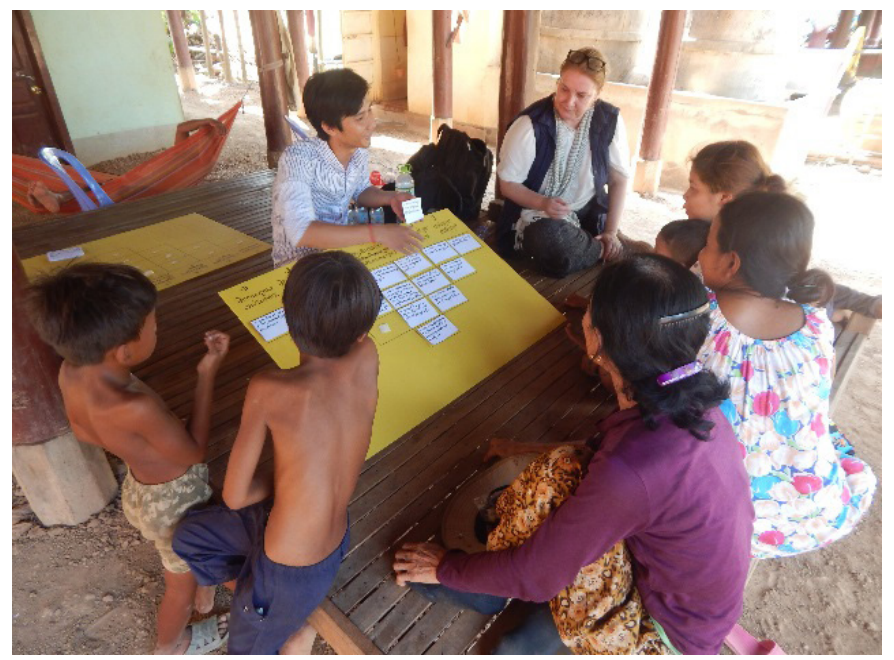

PHOTO 1. Q-sort focus group in Thma Reab, Cambodia. hazards as a result of multiple risk factors; (2) determine the various factors that can enhance resilience and adaptive capacities of flood-affected communities in a changing environment, and (3) provide examples of successful community-based flood management and climate change adaptation that can inform strategies in similar areas of the two countries. The remainder of this article describes the multi-method research approach and analytical framework (Section 2) and then discusses the findings at the landscape, community and household level (Section 3). Section 4 summarises the main results of the study and offers some concluding remarks.

\section{METHODOLOGY}

\subsection{Study sites}

\subsubsection{Prek Prasop District, Kratie Province, Cambodia}

The northeastern province Kratie is one of the most disaster-prone provinces in Cambodia, with floods being the most frequent and severe climate-associated hazard. From 1996 to 2017, flood events in Kratie province adversely affected more than half a million people, damaged 1,715 houses and destroyed about 165,000 ha of crops. One of the most severely impacted districts is Prek Prasop, stretching along the western banks of the Mekong River. Additional environmental and social risks stem from hydropower development in the upper Mekong River Basin and deforestation. The district has a population of over 68,000 people divided into about 15,000 families (National Committee for Decentralization and Deconcentration [NCDD], 2015). The research was conducted in a total of 11 villages in four communes, with the most intensive fieldwork carried out in four communities, namely Thma Reab, Ou Long, Dei Doh Kraom and Kbal Kaoh.

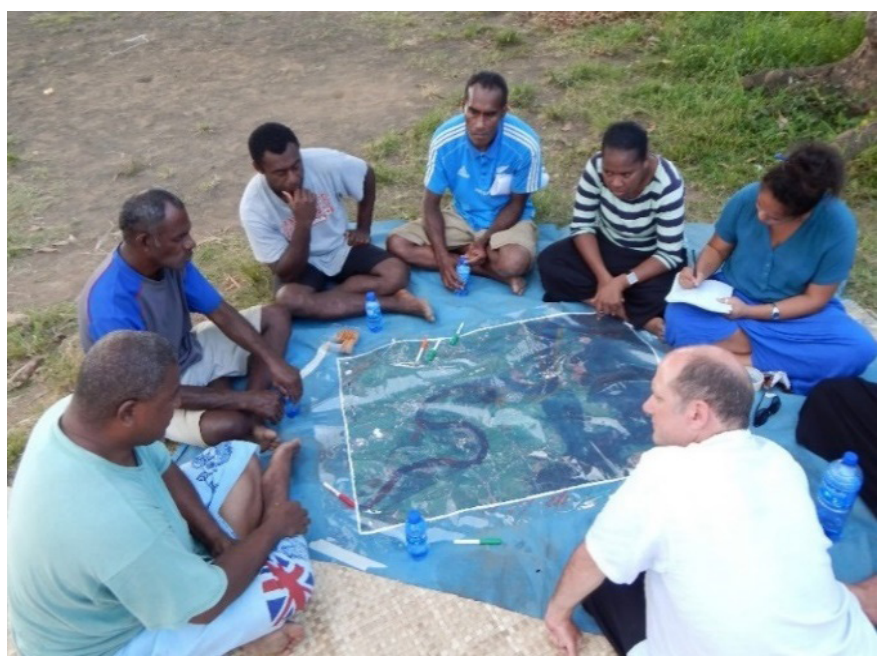

PHOTO 2. Participatory hazard mapping in Votua, Fiji. 


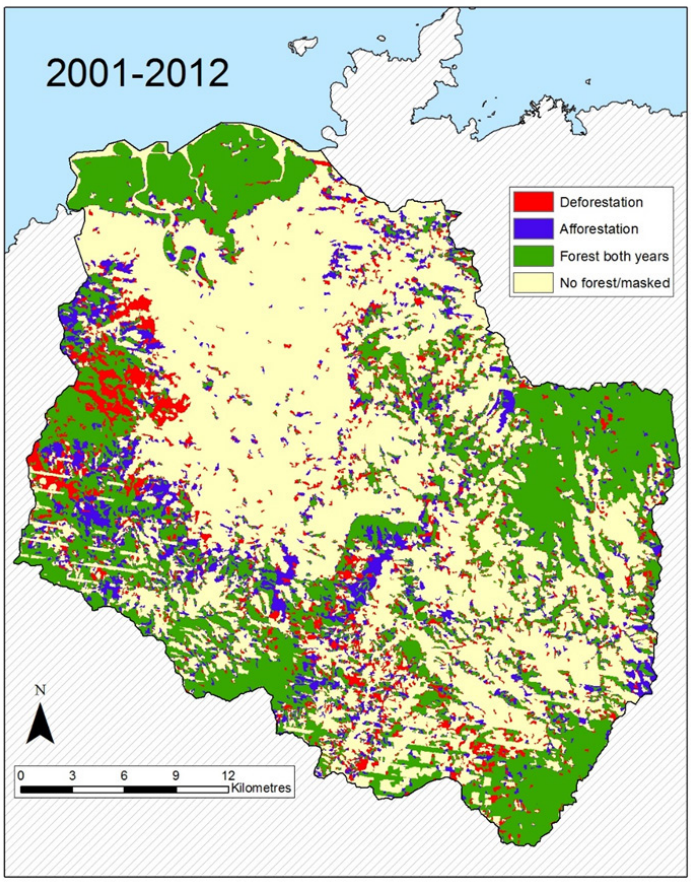

FIGURE 1. Change in forest/mangrove cover in the Ba River catchment from 2001-2012.

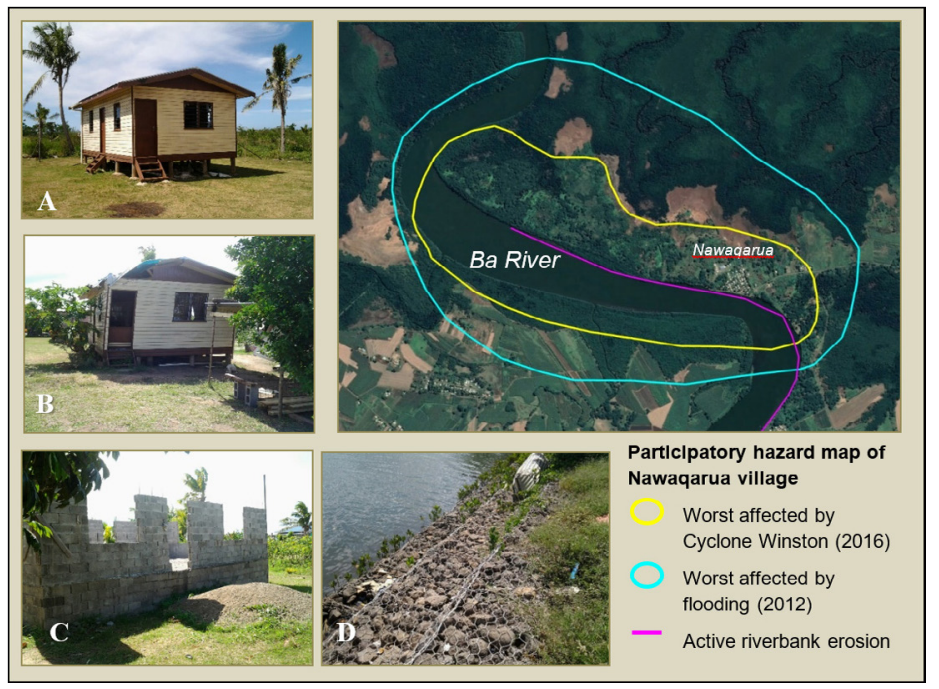

FIGURE 2. Illustration of exposure to multiple hazards at Nawaqarua village. The large map at upper right depicts hazard zones drawn by community members, indicating a spatial overlap of exposure to cyclones, flash flooding, and riverbank erosion. Inset photos (all taken within the village, indicated on map by "Nawaqarua"): A) New, government-funded house on stilts constructed to replace a dwelling lost in the 2012 floods; B) New house damaged by Cyclone Winston in 2016; C) New brick house under construction to replace house destroyed in Cyclone Winston; D) Engineering works to control riverbank erosion.

\subsubsection{Ba River Catchment, Ba Province, Viti Levu Island, Fiji}

Located in the most populated province of Fiji, the Ba River catchment in northwestern Viti Levu covers a total area of about $950 \mathrm{~km}^{2}$ (Brown et al., 2014). Approximately 46,000 people live within the catchment boundaries, of whom about one third are iTaukei (indigenous Fijians), and the remaining two-thirds are Fijians of Indian descent (Brown, Daigneault, Tjernström, \& Zou, 2018). Floods are the most frequent weather-related hazards that have affected communities in the downstream part of the Ba River catchment (Yila, Weber, \& Neef, 2013). In a historical analysis, Yeo, Blong, and McAneney (2007) identified 28 major floods that affected the lower Ba River catchment between 1892 and 1999, with an increased frequency recorded since the most disastrous flood event of 1931. Further floods with disastrous consequences for local livelihoods occurred in 2009, 2012 and 2018 (Yila et al., 2013; Neef et al., 2018). Even hillside villages in the upstream part of the catchment, such as Navala, recorded some degree of flooding. Apart from Navala, most research focused on three communities-Votua, Nawaqarua and Etatoko.

\subsection{Methods for data collection and analysis}

The study is based on various fieldwork phases conducted in both study sites between November 2015 and November 2018. The research team employed an action-research approach combining scientific knowledge with the elicitation of local knowledge and local capacity-building. Qualitative data was collected using informal research conversations, semi-structured interviews, in-depth narrative interviews, and focus group discussions. Various interactive and participatory methods, such as ranking exercises, Q-sort methodology (only employed in the study area in Cambodia, cf. Photo 1), and participatory hazard mapping (Photo 2), were employed to examine how communities and households cope with and adapt to frequent flood events in a multi-risk environment. Computer-assisted qualitative data analysis software (ATLAS.ti and NVivo) was used to analyze the qualitative data.

For the scientific assessment of flood risks, we collected various types of quantitative data, such as topographic and hydrological data, information on land use and farming systems, socio-economic conditions and local water management systems. Remote sensing (RS) techniques were employed to derive information such as soil characteristics and land and vegetation cover in the target basins. Remotely sensed data at multiple spatio-temporal scales were used to map land cover change in the Ba River catchment. The RS-derived data was validated through field surveys. For the case of Prek Prasop District in Cambodia, Synthetic Aperture RADAR (SAR) images captured every 12 days at $10 \mathrm{~m}$ resolution from the Sentinel-1 satellite were analyzed. Otsu's (1979) method was used to automatically determine a backscatter threshold for separating low-backscatter water areas from high-backscatter non-water surfaces such as soil and vegetation. Permanent water areas were classified by thresholding the mean backscatter derived from all images captured between 2015 and 2018. Flood dynamics were mapped for 2018 (a severe flood event) and 2016 (a 


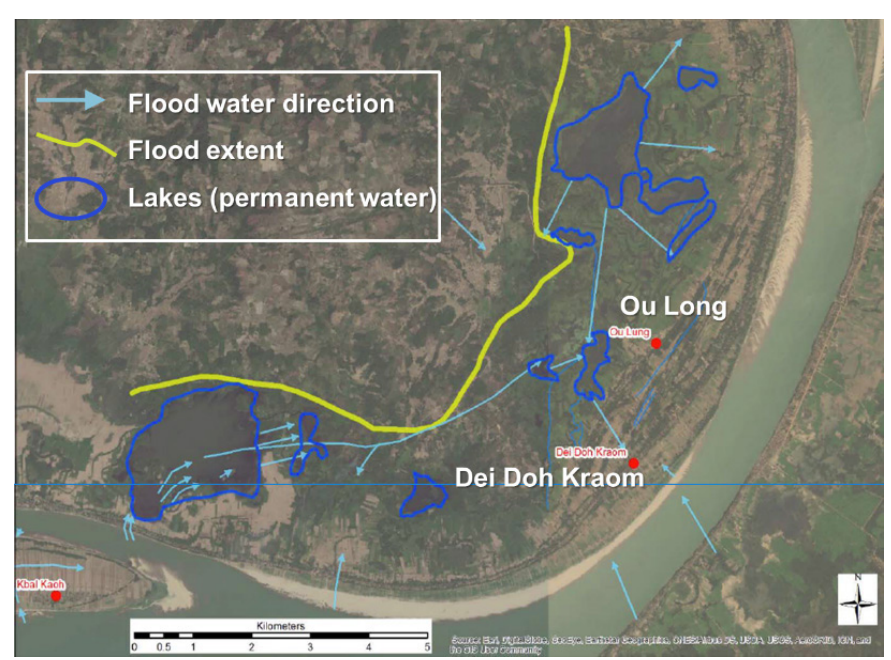

FIGURE 3. Flood water directions and flood extent in the lower part of Prek Prasop District (based on participatory hazard maps, M. Williams, June 2016).

drought year) by thresholding individual images.

Results from our study were reported back to the local communities as well as to government officials and NGO representatives in local dissemination workshops organized in 2019 to validate our research findings, share information and implement better flood protection and disaster risk reduction measures in the future.

\subsection{Conceptual framework}

In their working paper "Climate Adaptation, Local Institutions and Rural Livelihoods", Agrawal and Perrin (2008) argue that climate change is "likely to manifest around increased risks to rural livelihoods". These risks can be classified into four different types, including: risk across space, risk over time, risk across asset classes and risk across households (Agrawal \& Perrin, 2008). Risks are mitigated, according to Agrawal and Perrin, through correlated strategies of adaptation including mobility, storage, diversification, communal pooling and market exchange (Agrawal \& Perrin, 2008; Neef et al., 2018). Climate change adaptation is thus defined by the ability to achieve a "secure livelihood" in the post-disaster environment.

A "secure livelihood" is understood in our study as involving the intersection of food, water and energy security-as well as how security of these basic needs intersects with the security of sociocultural needs. A perspective of how the quality of these securities changes over time, in particular as a result of climatic variation, was crucial to the study. Communities and households were perceived as key actors in mitigating the effects of climate change and coping with flood impacts. Hence,

\begin{tabular}{|c|c|c|c|c|}
\hline Statements & Indicators & F1 & F2 & F3 \\
\hline 1 & In the case of flooding, we move our farm animals and other valuables to higher ground & $3^{*}$ & $2 *$ & $3^{*}$ \\
\hline 2 & We do not need to change our sowing and harvesting times to cope with flooding & $-1^{*}$ & 0 & $1^{*}$ \\
\hline 3 & During floods, there are more fish to catch which compensates for the crop damage & $-2 *$ & $-1^{*}$ & $-2 *$ \\
\hline 4 & We have changed our cropping systems to be better adapted to flood events & 0 & $-1^{*}$ & 0 \\
\hline 5 & $\begin{array}{l}\text { Many families have relatives in other locations that can support them during floods and } \\
\text { droughts }\end{array}$ & -1 & $-1^{*}$ & 0 \\
\hline 6 & Many villagers had to move away permanently because of frequent disasters & 1 & 0 & $-1^{*}$ \\
\hline 7 & During the flood, we grow crops in other locations where no flooding occurs & $-2 *$ & $1^{*}$ & $-1^{*}$ \\
\hline 8 & Some villagers have insurance coverage against disaster events & $-3^{*}$ & $-3^{*}$ & -1 \\
\hline 9 & Before the flood arrives, we store enough food and water in our houses & $2^{*}$ & $1 *$ & $2 *$ \\
\hline 10 & Sharing information with other households is very important during the flood & 1 & 0 & $2 *$ \\
\hline 11 & The government does not need to take any action in our community to manage floods & $-1^{*}$ & $-2 *$ & $-3 *$ \\
\hline 12 & Villagers do not support each other very much during floods and droughts & $2 *$ & $-2 *$ & $-2 *$ \\
\hline 13 & Our own knowledge and experience is sufficient to cope with floods & 0 & 0 & 1 \\
\hline 14 & We will need to grow different kinds of crops to cope with drought events & 0 & 1 & 0 \\
\hline 15 & The government needs to help us when we suffer from a drought & $1^{*}$ & 2* & $1^{*}$ \\
\hline 16 & Following disasters, many villagers seek work outside the village to cope with the losses & 0 & $3^{*}$ & 0 \\
\hline \multicolumn{2}{|c|}{ Percentage of explained variance of each Factor } & 35.37 & 31.65 & 16.29 \\
\hline \multicolumn{2}{|c|}{ Number of loading Q-sorts } & 5 & 6 & 2 \\
\hline \multicolumn{2}{|l|}{ Eigenvalues } & 4.60 & 4.11 & 2.12 \\
\hline \multicolumn{2}{|c|}{ Standard error of factor scores } & 0.22 & 0.20 & 0.33 \\
\hline
\end{tabular}

TABLE 1. Factor arrays for the three factors representing hazard adaptation approaches. Significant factor loading at: $+/-0.645(\mathrm{p}<0.01)-99 \%$ confidence level. 
their capabilities and constraints to alleviate climate-associated risks and adapt their livelihoods to a rapidly changing environment were the major focus of the study.

\section{RESULTS AND DISCUSSION}

\subsection{Landscape-level analysis of land use change, flood causes and flood extent}

Figure 1 shows significant areas of both deforestation and afforestation in the Ba River catchment over the period of 2001 to 2012. Overall, a greater area was afforested than deforested over the entire study period, resulting in a $15 \%$ increase in forest cover. Both deforestation and afforestation were concentrated in particular areas, the spatial arrangement of which influences the flood mitigation capacity of vegetated areas. Results highlighted the fine temporal scale of forest cover change in the upstream part of the

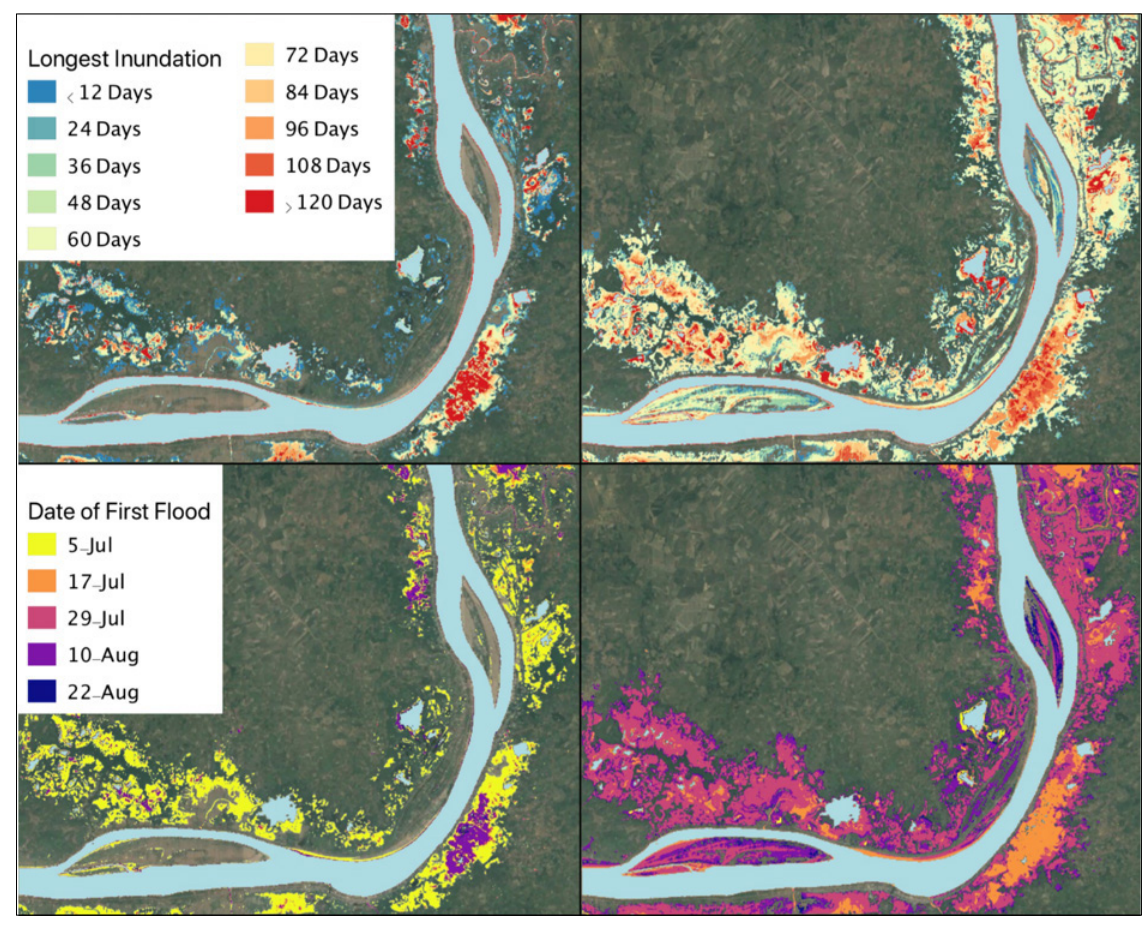

FIGURE 4. Flood dynamics as captured by Sentinel-1 SAR images. The maximum residence time of floodwaters based on images at 12-day intervals in 2016 (top left) and 2018 (top right). The first detected floodwaters in the 12-day interval images for 2016 (bottom left) and 2018 (bottom right).
Ba catchment. The ecosystem service role of forests in increasing flood resilience highlights the importance of incorporating forest cover change measurements in future assessment and monitoring of resilience in the $\mathrm{Ba}$ catchment.

Local knowledge was elicited during interviews and participatory hazard mapping sessions to gain insight into local perceptions of flood causes and understanding of flood flows and extent. Community members attributed the occurrence of severe floods to various factors, including upstream deforestation, high rainfall, sedimentation in the Ba River, and supernatural causes (flood disasters as an act of God). Research participants had mixed views on whether sediment dredging in the $\mathrm{Ba}$ River would mitigate flooding. Some villagers reported that mangroves areas were smothered by dredging mud, while others maintained that dredging created areas of higher or new land. Similarly, not all respondents thought that floods had only negative effects, as some noted an increase of nutrient-rich fine sediments and soil moisture. Participants in focus groups were able to show the distinct pathways of the flood and clearly delineate the extent of floods and cyclones as depicted in Figure 2 for the case of Nawaqarua village.

Similarly, in the study area in Cambodia, community members showed a profound knowledge of flood flows, extent and impacts, which was demonstrated during a series of participatory hazard mapping sessions (see Figure 3). At a local scale, this knowledge is more detailed than what can currently be gained from approaches in hydrology and remote sensing. Hence, drawing on both knowledge domains - local knowledge for detailed scale, scientific knowledge for broader scale and drivers - can provide communities, government decision-makers and scientists with a more holistic context to facilitate adaptation planning (for details on the methodological approaches to overcoming the challenges of combining scientific and local knowledge, see Pauli et al., submitted, and Mercer, Kelman, Taranis, \& Suchet-Pearson, 2010).

The strength of the scientific method lies in the accuracy with which the residence period of floodwaters could be measured (see Figure 4). The various maps in Figure 5 demonstrate high inter-annual variability in flood residence time and onset of floods. The year 2016 was a drought year, and there was a severe sudden-onset flood event in 2018 due to an upstream dam collapse in neighbouring Laos. The pattern of flood flows corroborates community member's descriptions of the directions of flood flows, the location of "safe" areas and the maximum flooded extent.

\subsection{Climate adaptation at community and household levels}

Rural communities in Kratie Province's Prek Prasop District have lived with seasonal floods for a very long time. They have built houses on stilts to be able to keep their belongings dry and to store enough food, water and fuelwood to survive a flood that can last between one and 


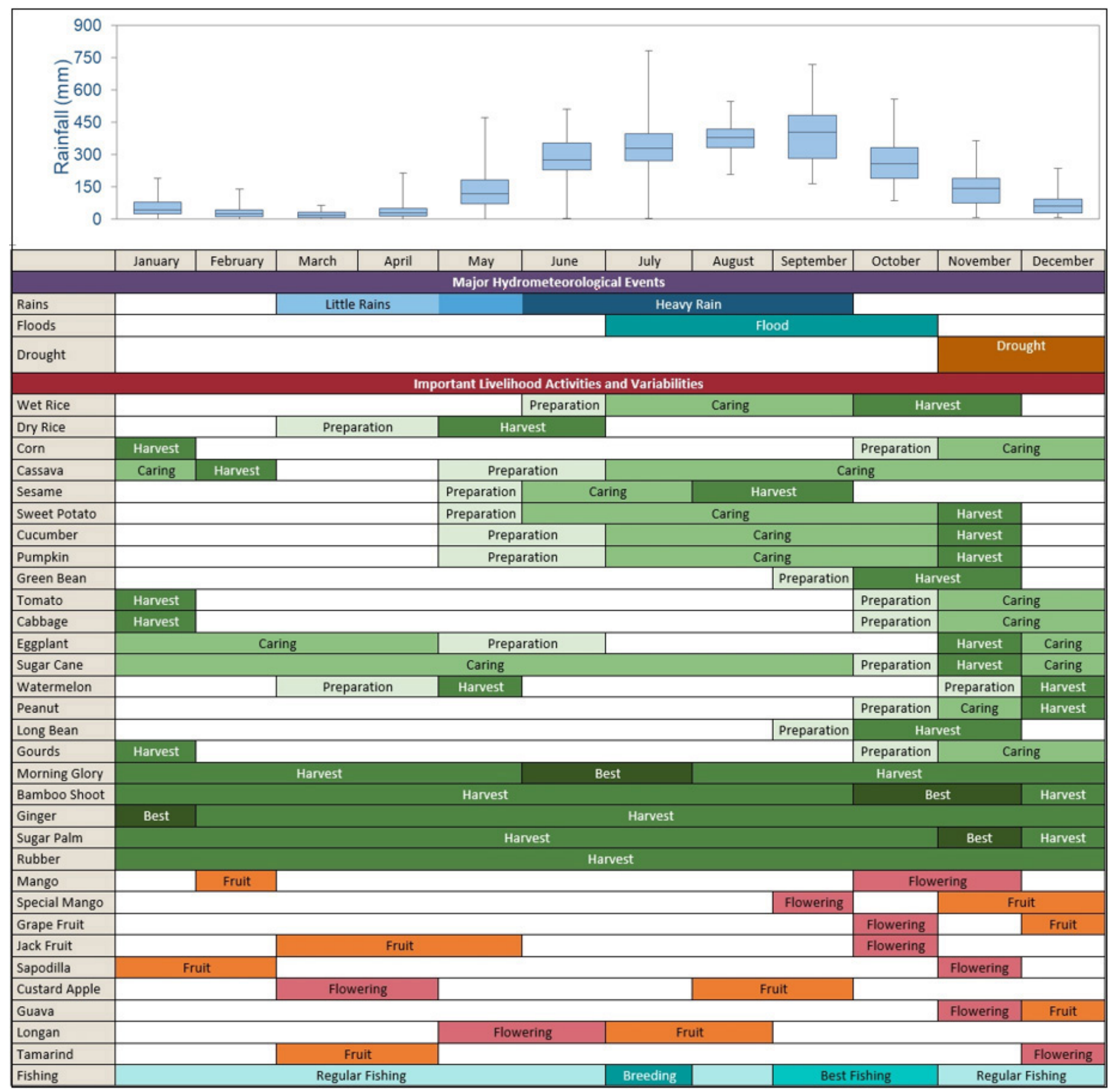

FIGURE 5. Seasonal calendar for the village of Dei Doh Kraom, Prek Prasop, Cambodia, collated from workshops conducted in November 2018.

two months. Wealthier households can further extend the height of their houses; thereby, they are in a much better position to cope with more extreme flood events than poorer households. More affluent households also have the financial capacity to buy farmland in safer places - such as upland areas - as a risk diversification strategy. Table 1 shows results from the Q-sort method, employed to understand differences in hazard adaptation approaches between household groups.

The columns in Table 1 are representative answers of three different groupings of participants (F1, F2, F3). The value in each column signifies the level of agreement for that statement of the groups (F1, F2, F3) that are associated with that Factor [ -3 (strongly disagree) -3 (strongly agree)]. If there is a *, then the value is significant, meaning that all the groups associated with that factor have expressed a similar sentiment.

All villagers participating in the $\mathrm{Q}$-sort focus groups saw moving their assets to higher ground and storing foodstuffs as a reliable coping mechanism. Fishing does not offset crop loss during a flood event, and insurance is not a common practice or is not considered a feasible adaptation mechanism by local people. There was variability in the degree to which villagers helped one another, but most villagers felt that the government could provide more assistance, particularly during times of drought. 
Villagers were indecisive as to whether they had sufficient knowledge to cope with flooding and whether crop diversification was appropriate for dealing with drought. Short-term coping strategies, such as finding temporary employment in neighbouring districts that are not affected by floods, were not distinguished from long-term adaptation strategies like adjusting cropping systems, as post-disaster recovery increasingly blends into the pre-disaster risk reduction phase, thereby blurring the boundaries between reactive and preemptive strategies.

Diversification was one of the types of adaptation practice which were less employed by female-headed households than male-headed households, according to findings from our household survey (Table 2). However, like for the other adaptation practices, the differences between male-headed and female-headed households were statistically not significant.

More detailed information on crop diversification in the communities in Prek Prasop District was gathered through seasonal calendars developed in focus groups. Figure 5 depicts a seasonal calendar based on the outcomes of a focus group in Dei Doh Kraom. This community reported the most diverse array of crops grown, thereby demonstrating a high potential of resilience to climate change and adverse weather events. The seasonal calendar includes the typical timing of important meteorological events (compared with rainfall data) and key livelihood activities. Crops depicted are a mix of those grown for home consumption and sold for income.

Research participants perceived that due to environmental change and upstream hydropower development, floods have become less predictable and more intense in Prek Prasop District. When the floods arrive in the villages, the male household members will bring all large livestock - cattle and buffaloes - to higher ground, where they stay with the animals until the floodwaters recede. Meanwhile, the women stay in the flooded village where they prepare energy for the family, collect fodder for livestock and take fish to the market. These floods cause mental stress and put lives at risk, but people have learned to cope through such temporary mobility patterns. Some communities have assigned certain places as communal refuge areas - such as a hilltop Buddhist temple ground in the case of Prek Prasop commune where all male community members can stay together for an extended period. In other communities (e.g. Koh Tasuy), by contrast, flood refuge areas are privately built and owned, hence being able to escape with large livestock to higher ground in those locations depends on individual households' land assets and financial capital.

In both study sites, social networks helped to reduce

\begin{tabular}{|l|l|l|l|}
\hline $\begin{array}{l}\text { Class of } \\
\text { adaptation } \\
\text { practice }\end{array}$ & $\begin{array}{l}\text { Male- } \\
\text { headed } \\
\text { households }\end{array}$ & $\begin{array}{l}\text { Female-headed } \\
\text { households }\end{array}$ & $\begin{array}{l}\text { Chi-square } \\
\text { (p-value) }\end{array}$ \\
\hline Storage & $89.52 \%$ & $82.93 \%$ & 0.262 \\
\hline Mobility & $64.52 \%$ & $63.41 \%$ & 0.898 \\
\hline Diversification & $71.77 \%$ & $60.98 \%$ & 0.195 \\
\hline $\begin{array}{l}\text { Communal } \\
\text { pooling }\end{array}$ & $66.13 \%$ & $63.41 \%$ & 0.751 \\
\hline
\end{tabular}

TABLE 2. Gender-based differences in the use of adaptation practices in Prek Prasop District. Note: Out of the 165 households included in the survey, 124 and 41 households were headed by male and female household heads, respectively.

vulnerability to hazards and insecurity. Strong bonds among community members and a culture of assisting one another during hard times were particularly pronounced in iTaukei (indigenous Fijian) communities in the Ba River catchment. In times of disaster, these social networks play a crucial role in resilience and recovery. Vulnerable community members - children, the elderly, people with disabilities and those who lost their homes - rely upon functioning social networks for support. Women in iTaukei communities were found to play a particularly important role in disaster response, often taking care of the most vulnerable, such as elderly relatives whose mobility was compromised.

Evidence from our research in iTaukei communities also suggests that Faith-Based Organizations (FBOs) are an integral part of local communities due to their spiritual roles in the everyday lives of people (cf. Cox et al., 2019). Given the importance of religious beliefs, FBOs are considered more trustworthy as they have more local knowledge and religious links with local communities than secular or international Non-Governmental Organizations (NGOs). Disaster relief efforts at the community level are often organized around church groups, with women groups playing a particularly prominent role.

Among Fijians of Indian descent who mostly live in scattered settlements of extended families, formal community emergency response was found to be virtually non-existent. Research participants stated that they relied primarily on informal networks, e.g. neighbourhood connections with other farmers or prayer groups. The lack of land ownership poses particular challenges for adaptation among these communities. Agricultural leases are often based on crop yields from the land. Hence, when flood events reduce crop yields, it was more difficult for tenants to pay the annual lease fee.

While there are (controversial) plans for iTaukei communities to be relocated from areas with substantial risk, there have been no such provisions for Fijians of 
Indian descent. Further, relocation without government assistance is complicated by the lack of available land and the high cost of surveying and titling land. There is also the risk that iTaukei relocations will displace Fijians of Indian descent, as experienced in the resettled Etatoko community where the lease of an Indo-Fijian tenant was cut short in order to accommodate the 17 relocated iTaukei households (Neef et al., 2018).

The examples of the first major climate-induced relocation processes in Fiji indicated in Neef et al., 2018, Box 1 provide a stark warning against external interventions that do not consider the social, cultural and historical context in a certain locality. Making decisions without proper consultation at the local level may make communities more vulnerable to the impacts of climate change or other - yet unknown - risk factors. The social fabric of a community can often change in response to relocation. This may trigger internal conflicts that disrupt the community's stability because the cultural and traditional values have not been adequately considered in the decision-making process. While the Fijian government's Planned Relocation Guidelines formally consider these aspects, they still need to stand the test in their implementation (Republic of Fiji, 2018).

\section{CONCLUSION}

Our study identified a high degree of congruence between the flood extent identified in participatory mapping sessions and the satellite-derived flood data which is consistent with previous research that found that there was a greater risk perception in areas of moderate or substantial flood hazards. This demonstrates that communities and scientists have a similar comprehension about the physical extent of hazards, although they might have different understanding about the causes of floods and the appropriateness of coping/ adaptation strategies.

Our study found that sociocultural, political and economic factors provide the basis from which communities and households make decisions on climate change adaptation strategies. All communities have adopted a wide range of strategies in line with Agrawal \& Perrin's (2008) framework according to their specific social, economic, and geographic situation. Access to resources, power, and information are key factors that inform communities and households in selecting appropriate adaptation strategies. External interventions that disregard the importance of local context are bound to fail. Our study also finds that the distinction between short-term coping strategies and long-term adaptation measures is problematic in contexts where communities and households are facing multiple risks and where post-disaster contexts tend to blend into new pre-disaster phases.

Inconclusion, adaptation frameworks need to accommodate diverse values, traditions, and social structures, where one-size-fits-all adaptation approaches should be avoided. As communities and households increasingly have to adapt to multiple risks, they find it harder to anticipate whether certain adaptation strategies are appropriate for a range of hazards or only alleviate a particular type of risk. Combining local and scientific knowledge domains is a promising pathway to enhancing the adaptive capacity of communities and households in rural areas of Cambodia and Fiji.

\section{ACKNOWLEDGEMENT}

We would like to extend our sincere gratitude to the Asia-Pacific Network for Global Change Research (APN) for providing generous funding over three years to support this research. We are particularly grateful for the extremely professional guidance and continuous support provided by Dr Linda Anne Stevenson, Ms Dyota Condrorini, Ms Nafesa Ismail and Mr Yukihiro Imanari throughout the preparation and implementation of the project. We extend our sincere thanks to all students and research assistants who participated in the fieldwork. The research team is grateful for the excellent support from the Ba Provincial Council, Fiji, and from the Ministry of Rural Development and the Kratie Provincial Authorities, Cambodia. We are also thankful for being accepted into the local communities by the local chiefs (turaga ni yavusa) and village leaders (turaga ni koro) in Fiji and the commune and village leaders in Cambodia. We thank all research participants for their hospitality during the fieldwork and for generously sharing their stories, experiences and insights with our research team. Finally, we are grateful to two anonymous reviewers whose thoughtful comments contributed to further improving the quality of this article.

\section{REFERENCES}

Agrawal, A., \& Perrin, N. (2008). Climate adaptation, local institutions, and rural livelihoods (Working Paper No. Wo81-6). Retrieved from http://www.umich.edu/_ ifri/Publications/Wo8I6\%20Arun\%20Agrawal\%20 and\%20Nicolas\%20Perrin.pdf.

Brown, P., Daigneault, A., Tjernström, E., \& Zou, W. (2018). Natural disasters, social protection, and risk perceptions. World Development, 104, 310-325.

Brown, P., Daigneault, A., Gawith, D., Aalbersberg, W., Comley, J., Fong, P., \& Morgan, F. (2014). Evaluating Ecosystem-Based Adaptation for Disaster Risk Reduction in Fiji. New Zealand: Landcare Research. 
Day, S., Forster, T., Himmelsbach, J., Korte, L., Mucke, P., Radtke, K., ... \& Weller, D. (2019). World risk report 2019-focus: water supply. Berlin, Germany: Bündnis Entwicklung Hilft.

Chand, S. S., Tory, K. J., Ye, H., \& Walsh, K. J. E. (2016). Projected increase in El Niño-driven tropical cyclone frequency in the Pacific. Nature Climate Change, 7(2), 123-127. doi:10.1038/nclimate3181

Cox, J., Varea, R., Finau, G., Tarai, J., Kant, R., Titifanue, J., \& Neef, A. (2019). Disaster Preparedness and the Abeyance of Agency: Christian Responses to Tropical Cyclone Winston in Fiji. Anthropological Forum, 3o(1-2), 125-140. doi:10.1080/00664677.2019.1647 833

Fernández-Giménez, M. E., Batkhishig, B., Batbuyan, B., \& Ulambayar, T. (2015). Lessons from the Dzud: Community-Based Rangeland Management Increases the Adaptive Capacity of Mongolian Herders to Winter Disasters. World Development, 68, 48-65. doi:10.1016/j.worlddev.2014.11.015

Hoang, L. P., Lauri, H., Kummu, M., Koponen, J., van Vliet, M. T. H., Supit, I., ... Ludwig, F. (2016). Mekong River flow and hydrological extremes under climate change. Hydrology and Earth System Sciences, 20(7), 3027-3041. doi:10.5194/hess-20-3027-2016

Lough, J., Gupta, A. S., Power, S. B., Grose, M. R., \& McGree, S. (2015). Observed and projected changes in surface climate of tropical Pacific Islands. In M. Taylor, A. McGregor, \& B. Dawson (Eds.), Vulnerability of Pacific Agriculture and Forestry to Climate Change. Noumea, New Caledonia: Secretariat of the Pacific Community.

Mercer, J., Kelman, I., Taranis, L., \& Suchet-Pearson, S. (2009). Framework for integrating indigenous and scientific knowledge for disaster risk reduction. Disasters, 34(1), 214-239. doi:10.1111/j.1467-7717.2009.01126.x

National Committee for Decentralization and Deconcentration. (2015). National Commune Database. Phnom Penh: NCDD.

Neef, A., Benge, L., Boruff, B., Pauli, N., Weber, E., \& Varea, R. (2018). Climate adaptation strategies in Fiji: The role of social norms and cultural values. World Development, 107, 125-137. doi:10.1016/j. worlddev.2018.02.029

Pauli, N., Williams, M., Henningsen, S., Davies, K., Chhom, C., van Ogtrop, F., ... Neef, A. (submitted). 'Listening to the sounds of the water': Bringing together local knowledge and biophysical data to understand the dynamics of climate-related hazards. International Journal of Disaster Risk Science.

Otsu, N. (1979). A Threshold Selection Method from Gray-Level Histograms. IEEE Transactions on Systems, Man, and Cybernetics, 9(1), 62-66. doi:10.1109/ tsmc.1979.4310076

Republic of Fiji (2018). Planned Relocation Guidelines: a framework to undertake climate change related relocation. Retrieved from https://cop23.com.fj/wp-content/uploads/2018/12/CC-PRG-BOOKLET-22-1.pdf

Yeo, S. W., Blong, R. J., \& McAneney, K. J. (2007). Flooding in Fiji: findings from a 100-year historical series. Hydrological Sciences Journal, 52(5), 1004-1015. doi:10.1623/hysj.52.5.1004

Yila, O., Weber, E., \& Neef, A. (2013). The role of social capital in post-flood response and recovery among downstream communities of the Ba River, Western Viti Levu, Fiji Islands. In A. Neef \& R. Shaw (Eds.), Risks and Conflicts: Local Responses to Natural Disasters (pp. 79-107). Emerald Group Publishing Limited, Bingley, UK. 